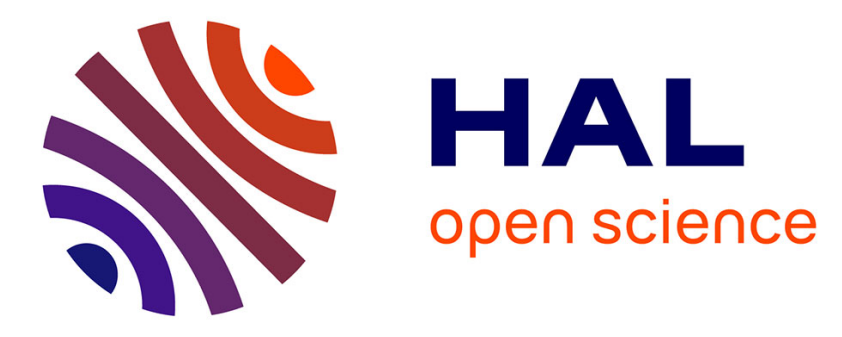

\title{
Teaching cursive handwriting: A contribution to the acceptability study of using digital tablets in French classrooms
}

Nathalie Bonneton-Botté, Claude Beucher-Marsal, Florence Bara, Julie Muller, Laurence Le Corf, Marielle Qué Mé Neur, Maud Dare

\section{To cite this version:}

Nathalie Bonneton-Botté, Claude Beucher-Marsal, Florence Bara, Julie Muller, Laurence Le Corf, et al.. Teaching cursive handwriting: A contribution to the acceptability study of using digital tablets in French classrooms. Journal of Early Childhood Literacy, 2019, pp.146879841983858.

$10.1177 / 1468798419838587$. hal-02319960

\section{HAL Id: hal-02319960 \\ https://hal.science/hal-02319960}

Submitted on 18 Oct 2019

HAL is a multi-disciplinary open access archive for the deposit and dissemination of scientific research documents, whether they are published or not. The documents may come from teaching and research institutions in France or abroad, or from public or private research centers.
L'archive ouverte pluridisciplinaire HAL, est destinée au dépôt et à la diffusion de documents scientifiques de niveau recherche, publiés ou non, émanant des établissements d'enseignement et de recherche français ou étrangers, des laboratoires publics ou privés. 
Teaching cursive handwriting:

\title{
A contribution to the
} acceptability study of using digital tablets in French classrooms

\author{
Nathalie Bonneton-Botte (1) \\ Laboratoire de Psychologie, Cognition, Comportement et \\ Communication, France
}

\section{Claude Beucher-Marsal}

Centre de Recherche sur l'Éducation les Apprentissages et la

Didactique, France

\section{Florence Bara}

CLLE-LTC, Université de Toulouse Jean-Jaures, France

\section{Julie Muller, Laurence Le Corf, Marielle Quéméneur and Maud Dare \\ Ecole Supérieure du Professorat et de l'Education, France}

\begin{abstract}
The process of teaching and learning handwriting is complex and laborious. A digital learning environment in the form of a tablet app could enhance teachers' knowledge of writer characteristics and their management of classroom diversity. This study aims to identify the needs of cursive writing teachers from a survey of 164 kindergarten teachers in France teaching writing skills for children aged 5 to 6 years. The results provide insights into teacher needs and, therefore, can be used to identify the acceptability criteria of a tool designed to scaffold the teaching of writing gestures. The results of needs analyses have been interpreted in the light of new scientific findings on reading and writing skills, and there is a discussion on the potential of such a digital learning environment for the classroom, particularly during the training and
\end{abstract}

\section{Corresponding author:}

Nathalie Bonneton-Botté, Laboratoire de Psychologie, Cognition, Comportement et Communication, Equipe d'accueil 1285, université de Bretagne Occidentale, France.

Email: Nathalie.bonneton@espe-bretagne.fr 
skills assessment phases. Questionnaire answers show that the teachers interviewed rarely use digital tools in the classroom and this prompts reflection on the value and meaning that preschool children give to the digital trace.

\section{Keywords}

Survey, teaching, handwriting, acceptability, digital device

\section{Introduction}

The acquisition of fluid, rapid and legible writing is key for academic achievement and preventing difficulties in school, not only because it seems to play a decisive role in building reading and writing skills (Berninger et al., 2002; Medwell and Wray, 2008), but also because pupils with weak writing skills are at a disadvantage throughout their schooling, particularly during written assessments (Rosenblum et al., 2006). In France, the educational and cultural system still favours cursive handwriting (Bara et al., 2016, 2011). The production of writing can be done either on digital media (keyboard, mobile phone and tablet) or by handwriting, using cursive or manuscript scripts. The combination of digital media and handwriting is possible when tablets are equipped with a stylus. In the school context, digital learning environments such as tablet apps can scaffold the teaching and learning process in an interresting way (Berninger et al., 2015; McKenna, 2012). Nonetheless, their use by teachers is conditional on their acceptability (Amadieu and Tricot, 2014). Most research highlights practitioners' interest in digital tools in emerging literacy (Burnett, 2010; Flewitt et al., 2015; Lankshear and Knobel, 2003). However, professionals' buy-in is not systematic. A recent evaluation of the uses of tablets in the school context shows a strong resistance from of French teachers who do not grasp their potentialities (Ferrière et al., 2012). The primary purpose of this study is to describe as precisely as possible the obstacles encountered by French teachers when they teach cursive handwriting. Better knowledge of the needs of the professionals should help us to make relevant recommendations to digital tools designers. Our second purpose is to characterize the current dispositions and uses shared by French teachers with regard to digital tools (and more specifically for tablet apps) dedicated to handwriting in the kindergarten (i.e. nursery school) context.

\section{Learning handwriting}

Cursive handwriting is characterized by static (e.g. written words on paper) and dynamic aspects (e.g. the process of producing written words) of 
movements that have to be produced quickly and fluidly. Handwriting movement is different from other types of movement because it is characterized by a strict sequentiality that takes a relatively long time to acquire (Longcamp et al., 2008). Researchers regularly highlight that mastering handwriting is a long and complex learning process entailing the development of motor programmes that stabilize the temporal patterns of writing and the ordered sequence of strokes making up the letters (Meulenbroek and van Galen, 1988; Thibon et al., 2018). With the help of visual and proprioceptive feedback that adjust writing action as it is being developed, these motor programmes - that evolve over time and are stored in long-term memory - are key for the acquisition of fluid, fast, and legible writing (Meulenbroek and Van Galen, 1988). The quantity and quality of sensory feedback processed and Knowledge of the Results (KR) are known to help the subject control movement during motor learning (Danna and Velay, 2015; Schmidt and Lee, 2005). KR can be defined as information provided to the learner after a response to let him or her know if he or she has achieved his or her goal (Salmoni, Schmidt, and Walter, 1984). KR is regarded as a crucial variable in the acquisition of motor skills.

\section{Teaching handwriting}

As sensory feedback and KR are important for the learning process, it seems highly appropriate to use devices that can enable learners to assess their movements and therefore realize their mistakes before the motor procedure has become automated. Even outside the field of motor learning, many studies have shown the critical role of feedback during the learning process (Salmoni et al., 1984). KR (Kluger and Denisi, 1996) is one form of feedback that needs to inform the pupil of his or her error and to provide the correct answer to be effective. Quick and immediate access to KR allows pupils to adapt their movement in real time. In the classroom context, when pupils learn to write, both self-regulation sources - sensory feedback and KR - may be present. For sensory feedback, teachers can still shape the learning environment through their use of materials, tools, resources and so forth to influence the sensory feedback received by the child during learning (e.g. asking students to write in the air, on the whiteboard or in sand). However, the teacher has no way of measuring how much feedback is effectively processed by the pupil or feedback's effectiveness in the learning process. For KR, children can be given production feedback (teacher debriefings covering static and dynamic aspects of the written product), but regulation by teachers is 
probably the type of feedback which is most often delayed, and logistical constraints often mean that the static and dynamic aspects of writing are rarely taken into account at the same time. Although techniques supplementing sensory feedback and KR have proved their efficiency in graphomotor therapy or in a one-to-one experimental device (Danna and Velay, 2015), technological innovations seem to be the only way of transposing such approaches to the classroom. To date, studies investigating the effectiveness of digital tools have mainly addressed the issue of their efficiency in terms of text production. As a teaching aid, digital tools offer new opportunities by facilitating collaborative writing (Choi et al., 2008; Warschauer, 2007) and self-assessment (Dragemark Oscarson, 2009). Researchers have also noted increased commitment to tasks using digital tools when compared to the written production of text on paper (Rogers and Graham, 2008). Thus, the potential that digital tools offer for fostering student motivation and engagement should be considered and digital tools for learning to write ought to be studied when introducing stylus-equipped digital tablets into the classroom for the teaching and learning of writing gestures.

\section{Digital tablets for teaching and learning handwriting}

Some technologies are currently designed to scaffold pupil learning (Berninger et al., 2015; McKenna, 2012; Puntambekar and Hübscher, 2005; Warschauer, 2007). Thanks to artificial intelligence, digital tablets enable data to be analyzed automatically to provide real-time feedback, and, when equipped with a stylus, tablets could potentially be used as a teaching aid for handwriting (Simonnet et al., 2017). In the field of educational research, it is widely recognized that assistive technologies and software designed to teach specific aspects of literacy facilitate the teaching-learning process, in particular because the technology makes one-to-one instruction possible (Chickering and Ehrmann, 1996; Van der Kleij et al., 2015).

However, there is no consensus on the more specific question of whether digital tablets help children in the acquisition of handwriting. Patchan and Puranik (2016) did not find any positive effect of the extrinsic feedback provided by a tablet when children learnt to write uppercase letters with a stylus-equipped tablet in comparison to paper and pencil. In contrast, through analyzing some of the dynamic properties of handwriting movements among kindergarten pupils and first graders, Jolly et al. (2013) showed a positive effect of learning to write cursive letters on a tablet versus on paper, with reduced letter size and increased fluency among learner writers who were 
training on a tablet. Although the authors could not identify the reasons behind this positive impact, it could be related to the motivational dimension of learning on a tablet or the availability of a dynamic model (video model illustrating the production of cursive text). The contrasting results might be explained by the difference between the type of analysis that focuses on the handwritten product (number of letters correctly written in Patchan and Puranik's 2016 study) versus that in a study that focuses on the handwriting process (fluency in Jolly et al.'s 2013 study). Alamargot and Morin (2015) highlighted the potential difficulties experienced by second graders when using tablets in this context. Comparing the characteristics of writing on a tablet screen versus on paper, the authors found that the different degrees of friction between the two media had an impact on the writing process: pause duration significantly increased when using a digital tablet.

Professionals' reservations about new technologies may also be an obstacle to the use of tablets as a teaching tool for writing (Ferrière et al., 2012). Such resistance to digital tools was reflected in the adverse media reaction in France - a country highly attached to cursive handwriting (Baraud, Bril, and Acioly-Régnier, 2018) - following the Finnish Ministry of Education's decision to make cursive handwriting classes non-compulsory and to offer keyboard learning instead, as in the United States (PBS Learning Media, 2015). This decision caused controversy among education professionals in France. Such strong reactions should inform researchers that the study and development of digital devices should always be culturally situated, and that educational practices and lessons are still largely determined by the beliefs and representations underpinned by 'an ecology of learning' (Bril, 2002). Thus, as well as being useful and usable (Amadieu and Tricot, 2014), a digital device must be acceptable as regards the needs of institutions, learners and teachers (Boissiere et al., 2013; Ferrière et al., 2012; Tricot et al., 2003).

To be relevant, the design of a digital handwriting assistance tool should facilitate assessment of the static and dynamic characteristics of handwriting and provide each student with knowledge of the result during the process of learning. Furthermore, to be acceptable, the design of this tool should integrate teachers' needs and beliefs concerning the learning of writing in a novice writer. Finally, the needs of school institutions that emerge from school curricula should be considered.

\section{From French institutional recommendations to teaching practices}

Educational policy research highlights that learning literacy standards influence teacher's writing instruction (McCarthey, 2008). Therefore, some 
professional needs and obstacles encountered by teachers are partially linked to syllabus implementation. Teachers often comment on a lack of time to complete the learning process, a difficulty in applying it to struggling students or a lack of understanding of the theoretical orientation of official statements (Goh et al., 2005; Troia and Graham, 2016).

In France, the 2002 syllabus for kindergarten stages sets out that by the end of the final year, a child must be able to write a sentence with cursive allographs. In 2006, official literacy documents highlighted the importance of teachers paying attention to the cursive learning process and not only to the result: 'Cursive writing is used in situations controlled by the teacher who will check each child's progress in stroke direction, and letterforms and their ligatures' ${ }^{1}$ (Ministère de l'éducation nationale (MEN), 2006: 111).

The 2008 syllabus did not set out many provisions for cursive writing. Compared to the previous text, the notion of ability was added: 'Cursive writing is offered to all kindergarten children, as soon as they are able', but 'able' is not defined. On this point, the 2015 recommendations are in the same spirit as the 2008 ones: 'the teacher will decide when the time is right for children to handle some of the writing activities led by adults' (MEN, 2015: $7^{2}$ ). Once again, no assessment criteria are set out.

Recent official statements by the French Education Ministry recall that handwriting is indeed a motor activity, but with meaningful intention: 'As the aim is to construct the symbolic value of letters, teachers shall ensure that they never isolate the three components of writing: semantic (the meaning of what is written), symbolic (alphabetic code) and motor (graphic dexterity)' (MEN, 2015: $8^{3}$ ).

In addition to these specific recommendations, the skills framework for school teachers (MEN, 2013) called for teaching and educational work to be adapted to pupil diversity. While it has been shown that digital environments make learning easier, thanks to the one-to-one instruction modality (Chickering and Ehrmann, 1996; Van der Kleij et al., 2015), the 2015 syllabus asks nothing specific of teachers in this area. Digital environments, computers and tablets are mentioned only once as possible tools to train pupils.

\section{Objective}

Teachers' interpretations and beliefs of curricula are important to understand because teachers are frontline implementers of such curricula and use them to shape their classroom instruction and assessment practices (e.g. Porter et al., 
2014). In the field of cursive writing, the only recent French study on cursive writing found that teachers place a high value on cursive writing, and most of them believe that educational computer tools should not be a replacement for teaching cursive writing (Baraud et al., 2018). Innovative technological devices are often useful and well designed but do not always find their place among users for reasons of acceptability (Amadieu and Tricot, 2014; Tricot et al., 2003). Therefore, understanding teachers' acceptability conditions for using a digital tablet for learning how to write is a key issue in the design process of kindergarten teaching-learning tools. This exploratory study accompanies a research project called 'intuiscript' that proposes to design a digital notebook ('Kaligo') to support cursive handwriting teaching. 'Kaligo' is an application for stylus-equipped digital tablets. Its real-time handwriting analysis devices provide learner writers with immediate KR (Simonnet et al., 2017).

This study has two objectives. The first is to understand how teachers translate three complex French institutional requirements (MEN, 2008, 2015) (i) identify pupils who are able to start learning cursive writing, (ii) ensure a the control of the handwriting process by his/her presence near the child and (iii) manage diversity. Given the complexity of institutional recommendations and of the learning process covering cognitive, motor and perceptual components, we hypothesize that the professional obstacles encountered by teachers will be revealed in questionnaires as lack of response or consensus in professional teaching practices, as already highlighted in other countries (Labrecque et al., 2013). The second objective is to identify some acceptability criteria for a digital tool that supports cursive writing teaching-learning in France. For that, uses and representations linked to digital tools dedicated to the handwriting domain will be investigated.

\section{Method}

\section{Sampling procedure}

The survey was sent to all kindergarten teachers last year (766 in total) in the Brittany region of France; 164 teachers answered, i.e. 21 per cent of the target population, which is highly representative in terms of expected criteria (see Dillman et al., 2009). Table 1 presents the survey population characteristics. While all had kindergarten experience, at the time of the interview, 53 per cent were teaching in the last (third) year of kindergarten (students aged 5 to 6 years). 
Table I. Summary of the survey population characteristics.

\begin{tabular}{lc}
\hline Average age & 42.80 \\
\hline Standard deviation of age & 7.73 \\
Number of women & 162 \\
Number of men & 2 \\
Average number of years of professional & 16.61 \\
$\quad$ teaching experience & \\
Average number of years of kindergarten & 9.26 \\
teaching experience & \\
\hline
\end{tabular}

\section{Questionnaire dissemination}

The questionnaire was created using Limesurvey software (Schmitz, 2016). The Management of each institution then disseminated it via their digital workspace during semester 1, 2017. All respondents were voluntary; the institutions placed no obligation on teachers to participate. The questionnaire was available online for three months and the response time was between 20 and 40 minutes.

\section{Survey instrument}

The survey's form and content were inspired by existing surveys (Bara et al., 2011; Labrecque et al., 2013 Paoletti, 1994; Troia and Graham, 2016), and the categories proposed in the multiple choice questions were based on current scientific knowledge on emergent writing and reading skills (Bara and Bonneton-Botté, 2017; Puranik et al., 2011, 2014). A first exploratory questionnaire had been conducted with 60 teachers one year previously (Bonneton-Botté et al., in press). The questionnaire was improved following an initial analysis of the results; in particular, the proposals in the multiple choice questions were enriched. There were 17 guided, open or semidirective questions, most of which were multiple choice, and respondents were asked to prioritize their first three choices. Demographic data were collected on age, gender and teaching experience, more specifically in the final year of kindergarten. There was a space at the end of the questionnaire for participants to make any open text responses if they so wished.

To address both objectives, the questionnaire was structured into different blocks of issues:

- The first block concerned the criteria used by teachers to decide when a child is able to learn cursive handwriting: one multiple choice question was on the 
cognitive, linguistic and motivational criteria used when a pupil is able to learn cursive handwriting, followed by two on motor aspects (motor criteria used and how teachers define the notion of fine motor skills).

- The second block set out to identify the gestures and professional tools that characterize cursive writing teaching in the final year of kindergarten in France. This article will analyze more specifically the question of how teachers respond to the 'teacher presence' requirement. Four questions were on diversity management and writing difficulties.

- The last block of questions concerned the use of digital tools for teaching cursive writing: materials available in the school/classroom and how these materials are used when teaching cursive writing. The last two questions concern teachers' representations about young children's writing on stylus-equipped digital tablets.

\section{Data analysis}

Although the survey contained 17 questions, this article will only deal with those related to the two objectives: (i) analyze the professional obstacles inherent to implementation of the syllabus regarding cursive handwriting and (ii) identify the perception and use of digital tools dedicated to the handwriting domain. Descriptive statistics, that allow an analysis of response/non-response distribution (percentages), were used to report on teacher practices and beliefs. For open-ended questions, responses were analyzed and categorized so they could be presented synthesized.

\section{Results}

\section{'Able' to learn cursive handwriting}

We first asked teachers what they understood by 'being able to learn cursive handwriting', a phrase that has appeared in the kindergarten syllabus since 2008. They were asked to select and prioritize the three criteria they felt were the most important among a list of motor, cognitive and motivational indicators currently mentioned in the literacy literature (Figure 1).

Among eight criteria (i.e. enjoyment of writing, global recognition of words, starting to decode, able to distinguish alphabet signs, knowledge of letter names, knowledge of letter sounds, knowledge of letter gestures, fluency in graphomotricity), three stand out as the most important: enjoyment of writing (pupil motivation), fluency in graphomotricity and knowledge of letter gestures. It can be observed that the reading process set of items were rarely selected (i.e. global recognition of words, starting to decode, knowledge of letter sounds), except for knowledge of letter names, which was quoted 28 times. 


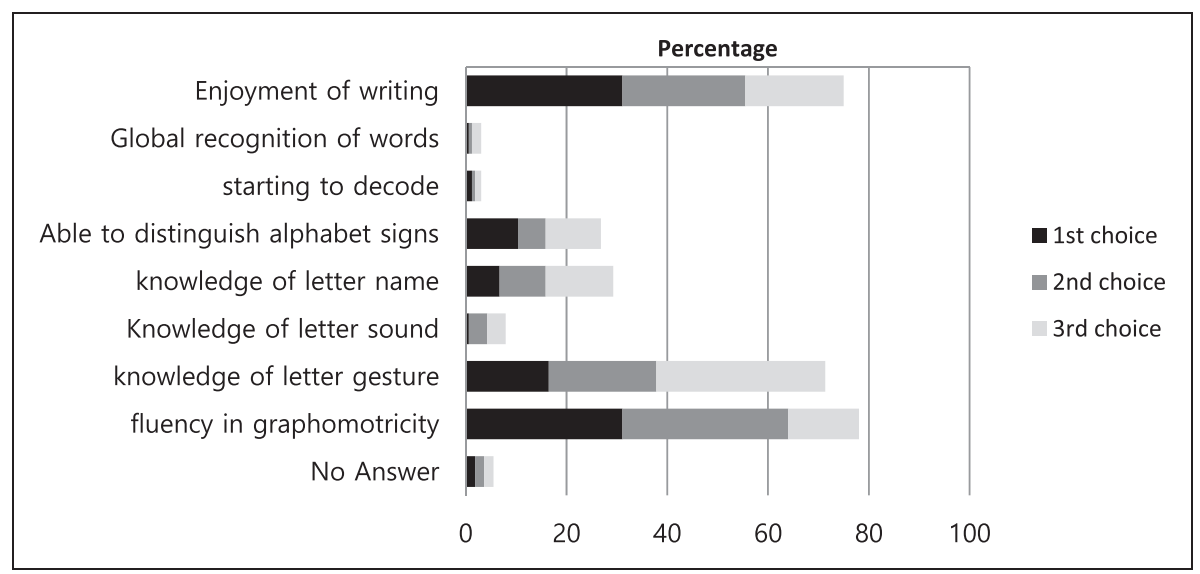

Figure I. The three most chosen criteria for starting to teach cursive handwriting with pupils in the final (third) year of kindergarten in percentage.

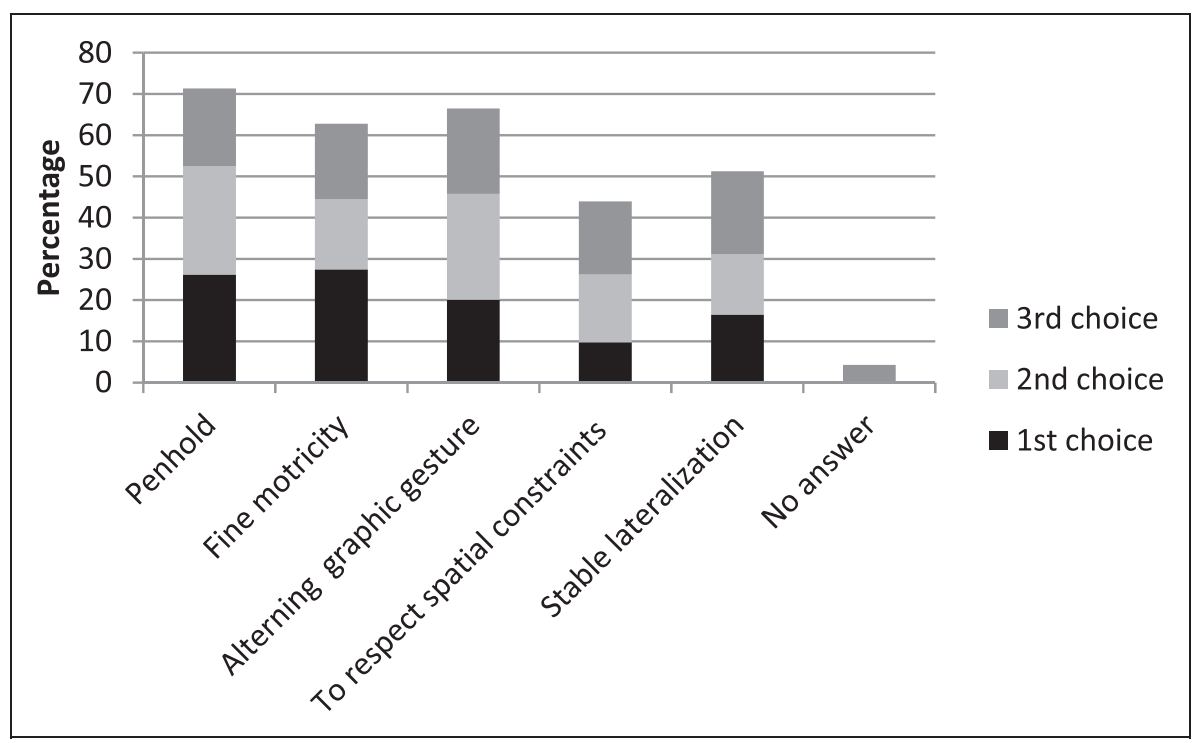

Figure 2. Teachers' first, second and third most important motor criteria for deciding when a child is able to learn cursive handwriting in percentage.

A second question asked teachers to specify their motor criteria for deciding that a child is able to learn cursive writing (Figure 2).

Considering the three most selected motor criteria, the responses are relatively disparate. Nevertheless, the first three choices show that penhold and 


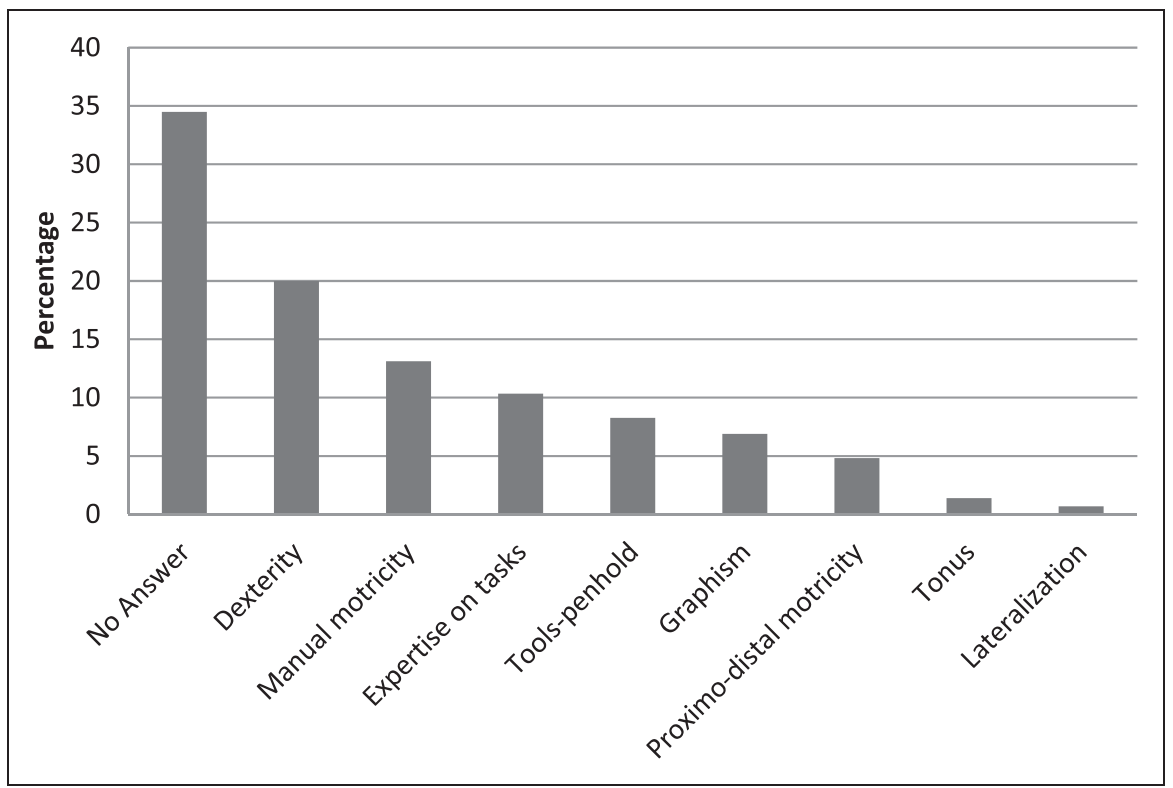

Figure 3. Categorization of answers to the question "What does "fine motor skills" mean to you'?

fine motor skills receive particular attention. The first choice often involves fine motor skills: whenever teachers said that fine motor skills were one of their criteria, we asked them to clarify what they meant by fine motor skills (What does 'fine motor skills' mean to you?) (145 answers). Figure 3 summarizes the categorization of answers obtained.

'What does "fine motor skills" mean to you?' was an open question. For this open-ended question, the responses were analyzed and categorized so that they could be synthesized and presented. The categories obtained are listed in Figure 3. To this question as well, the answers are highly disparate. Over one third of participants were unable to explain what they meant by fine motor skills. For 20 per cent of them, fine motor skills involved eye-hand coordination and at the same time the ability to realize precise movements with the fingers. The third most common response was manual motricity (13 per cent). Here, teachers evoked hand musculature or manual ease without referring to visual coordination. Eleven per cent of answers referred to performance on a manual task (being able to cut with scissors/thread beads) and 6.9 per cent referred to performance on a graphic task. About 7 per cent of teachers considered that fine motor skills can be observed by penhold. Overall fine motor skills were rarely related to tonus, posture (proximo-distal motricity) and lateralization. 


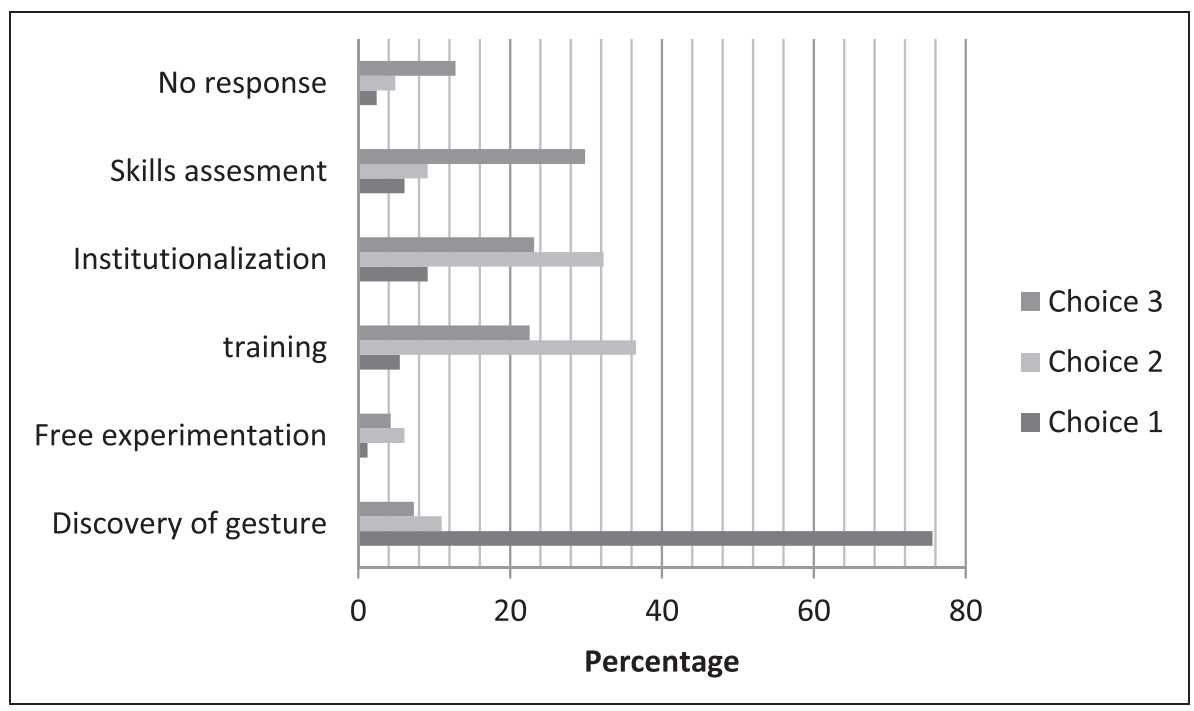

Figure 4. Hierarchization of learning phases in which teachers consider teacher presence to be essential (Three first choices in percentage).

\section{Teacher presence for learner writers}

At what point in the teaching process do teachers consider their presence to be essential? Respondents were asked to rank, by order of importance, the different steps involved in the teaching process as regards teacher presence. Five different phases were proposed: discovery of gesture, training, free experimentation, institutionalization and validation. The hierarchization of choices is presented in Figure 4.

Of the 164 teachers who responded to this question, the vast majority consider discovery of gesture to be the most essential phase for teacher presence. Institutionalization and training were the second most frequently chosen responses. The phases of free experimentation and skills assessment are cited the least frequently.

\section{Managing diversity from a 'discovery of gesture' perspective}

Teachers were first asked if they usually arranged specific activities for pupils experiencing difficulties: 85.37 per cent responded positively, 9.15 per cent responded negatively, and 5.49 per cent did not answer. For each positive answer, respondents were asked to specify the activities arranged to manage these difficulties ('If yes, specify the types of activities you offer pupils with 


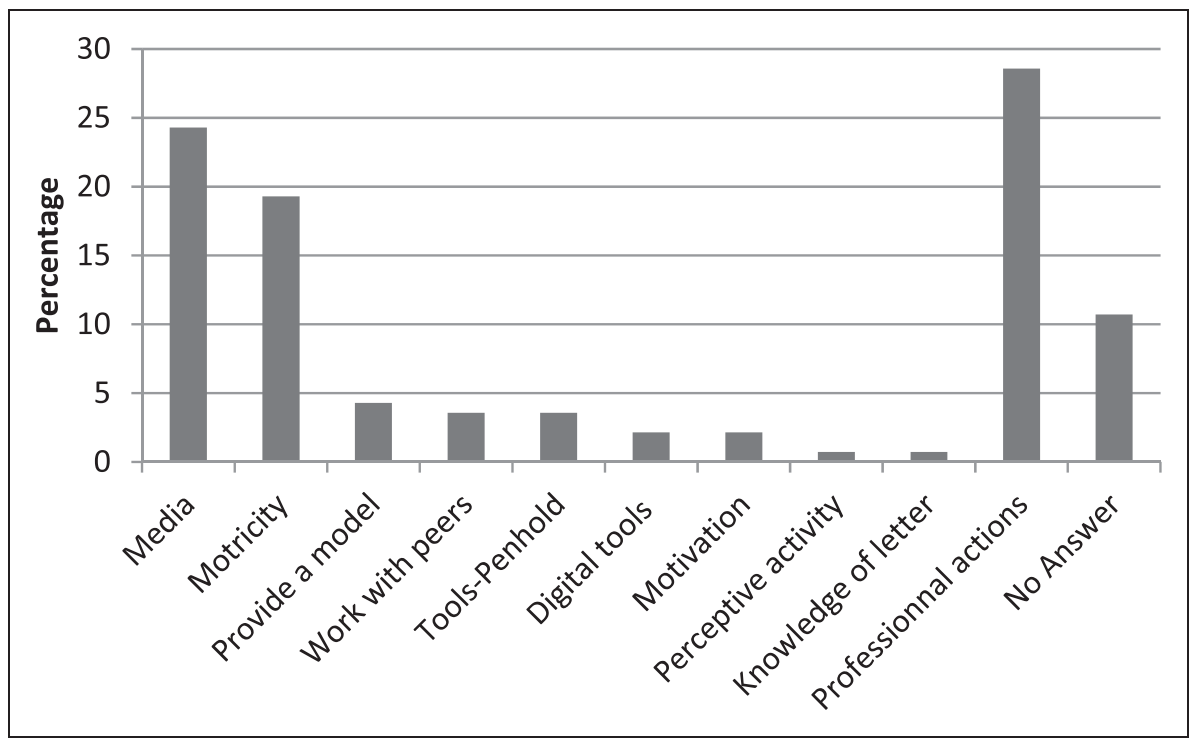

Figure 5. Categorization of answers to the question "How do you help children with learning difficulties (free answer)'?

learning difficulties'). Fifteen teachers did not answer this question. By analyzing keywords and proposals, we grouped 11 categories of responses, including 'no answer'. The distribution of the different categories is presented in Figure 5.

Analysis of the responses shows that specific activities often consist of changing the medium used for the graphic surface: table, sand and flour are frequently cited and sometimes the word media is used without further elaboration. Almost 20 per cent of teachers offer motor activities (e.g. modelling clay, beads, games to loosen fingers). One third of answers state a professional action without going into further detail (enhancement, guidance and alleviation). Specific activities linked to penhold are rarely evoked, likewise for the use of digital tools and motivation. The perceptual dimension of the act of writing was only mentioned once.

\section{Equipment, representation and use of digital tools}

Teachers were first asked to specify the digital materials available in the classroom from a list of choices (interactive board, computer, video projector, slideshow, digital tablets for teachers and digital tablets for pupils). Thirtyone respondents reported that they had no equipment. Respondents with 
Table 2. Categorization of explanations on the difference between tablet and paper surfaces.

\begin{tabular}{lc}
\hline & Percentage \\
\hline Unclear & 5 \\
No answer & 69 \\
Impermanent & 12 \\
Writing on a tablet is more difficult & 8 \\
Motivation for tablet & 6 \\
\hline
\end{tabular}

equipment were asked if they used it to teach handwriting: 5.5 per cent did not respond and 76.2 per cent said they did not use any digital materials to teach handwriting. Twenty-nine respondents (18.3 per cent) reported using digital devices: nine used an interactive board, seven a computer, nine video-projectors or slideshows, three had their own digital tablet and only one offered digital tablets to pupils. As we wanted to know if there was a difference for teachers between writing on paper and on a stylus-equipped tablet, we asked the following question: 'There are currently applications for learning to write on tablets with a stylus. From the child's perspective, do you think there is any difference between the trace left on paper and the trace left on a tablet'? If the answer was yes, teachers were asked to explain the difference. Eleven per cent of respondents did not answer, 37 per cent did not consider there was a difference and 52 per cent $(\mathrm{n}=84)$ considered there to be a difference. Explanations about differences are presented in Table 2.

Most respondents could not explain why they consider there is a difference between these two writing media. Only 6 per cent of respondents were in favour of writing on a tablet; they consider this medium to be more motivating. Others consider that writing on a digital tablet is more difficult ( 8 per cent) or that the fact that the trace disappears with the tablet might be a problem for pupils (12 per cent).

\section{Discussion}

A review of research conducted by Lankshear and Knobel (2003) highlights that early childhood is even more under-researched than other age ranges. However, digital environments with artificial intelligence could potentially modify future professional practice in the field of early literacy education (Flewitt et al., 2015). For instance, if considerable training is necessary to 
acquire quality handwriting (Hoy et al., 2011), the amount of time dedicated to teaching handwriting varies from 2 minutes to 1 hour per day (Graham et al., 2007). The use of stylus-equipped digital tablets with artificial intelligence - providing learner writers with immediate $\mathrm{KR}$ and differentiated lessons - could significantly improve the teaching process as they enable one-to-one instruction (Berninger et al., 2015; McKenna, 2012; Simonnet et al., 2017; Van der Kleij et al., 2015). However, the professional needs of teachers and institutions need to be taken into account when designing acceptable digital devices (Amadieu and Tricot, 2014; Flewitt et al., 2015). A digital teaching/learning tool should attempt to meet the needs of cursive writing kindergarten teachers and their pupils whose cognitive perceptual and motor development is highly diverse (Accardo et al., 2013). We believe that digital devices could be integrated into a field of promoted actions (Bril, 2002; Baraud et al., 2018) only if they overcome the obstacles encountered by teachers in the classroom and do not clash with shared cultural values and beliefs in the educational community. The present study, which took place in a French cultural context, had two main objectives: First, to discover how French kindergarten teachers grasp certain official recommendations regarding cursive handwriting acquisition (i.e. identify the criteria they use to decide when a pupil is able to learn cursive handwriting, understand how they ensure their presence during the learning process and how they manage diversity in learning handwriting). Given the complexity of institutional recommendations and of a learning process with cognitive, motor and perceptual components, we hypothesized that the professional obstacles encountered by teachers would lead to a lack of consensus in professional teaching practices and thus in responses to the questionnaire, as has already been underlined in other studies (Baraud et al., 2018; Labrecque et al., 2013). Second, given that this is a preliminary study for the design of a digital device (stylus-equipped digital tablet) to support the teaching of handwriting, we set out to assess the representation and use of digital devices for teaching handwriting in France.

When teachers were asked to explain how they decided on a pupil's readiness to learn cursive handwriting, the majority cited pupil willingness for writing activities. The importance given to motivation here could refer to the semantic component of writing in current kindergarten school syllabuses (MEN, 2015). We assume that the teacher will ensure the pupil has made the link between reading and writing before entering into the systematic learning of cursive writing. For some teachers, this means knowledge of letter-related gestures, which is a decisive indicator. What stands out here is the attention paid to the motor component of writing activity. This 
attentiveness to the motor component when entering the learning process of writing has also been observed in Quebec (Labrecque et al., 2013). Knowledge related to the symbolic component (i.e. letter names, early understanding of the alphabetic principle, word recognition, decoding and knowledge of graphemes) does not seem to be a preferred indicator. As responses heavily favour the semantic component (i.e. enjoyment of writing) over motor and symbolic ones, it would seem that the government recommendation not to isolate these three components is a challenge in practice, as it is the conjunction between semantic, motor and symbolic conditions that should be taken into account when judging if a child is able to learn cursive handwriting. Considering recent scientific developments in this field, it may be time to call into question the recommended approach of using these different components at the same time. As the development of writing skills is gradual and sequential, Puranik and Lonigan (2009) recommend that no formal instruction of writing take place while the child is still scribbling and not advanced enough in writing first names. In the present study, while 'writing first name' was not offered as a criterion for formal learning applicability in this study, only 10 per cent of teachers chose the criterion 'distinguishing signs that belong/do not belong to the alphabet' as first choice for deciding when a pupil can formally start to learn to write. The signs of interest shown by children with regard to writing activities and chosen by teachers as the decisive criterion still need to be clarified.

In clarifying the criteria used by French teachers for the motor component, a variety of responses reflected a lack of teacher consensus. In line with the study conducted in Quebec by Labrecque et al. (2013), this lack of consensus shows that practices are not sufficiently guided by scientific, research-based knowledge. For example, penhold was frequently cited as an indicator that a pupil is able to start learning cursive writing, but there are currently no empirical data supporting this (Schwellnus et al., 2012).

Teachers mostly waited for pupils to show interest in writing situations before they proposed cursive writing learning. Previous research in the related field of written production showed that in elementary school, pupil motivation and commitment were increased through the use of digital tools (Jolly et al., 2013; Rogers and Graham, 2008). Nevertheless, the question may arise whether emphasis on the semantic component will be the same when cursive writing activities are offered on a digital tablet. In kindergarten classrooms, will cursive writing on a stylus-equipped digital tablet have the same meaning for pupils and teachers? For most of the French teachers surveyed, the status of the trace is the major difference between paper and digital media. This 
perceived difference, which mainly seems to be intuitive as it is complicated to explain, is negative for some teachers; either they say that the screen surface makes writing more difficult as has already been highlighted in some studies (Alamargot and Morin, 2015; Patchan and Puranik, 2016), or they consider the impermanent written trace to be meaningless for young children. This perception probably refers to the fact that kindergarten children making their first written productions generally wish them to be read by their teachers or parents. It is important for the child (and probably for the teacher) to take the production home and to have it read or viewed. For the different members of the education community, it is most likely a defining moment for linking the three elements of writing, namely, the semantic, symbolic and motor components. Thus, from an acceptability perspective, even if writing on a digital tablet is considered motivating and positive (Berninger et al., 2015; Jolly et al., 2013), it seems that a digital tool for teaching/learning cursive writing should at least present the following two characteristics: (i) static and dynamic characteristics of the production accessible at any time by teacher/child and (ii) productions able to be projected, printed or sent for the written trace to acquire its communication function.

The 2006 and 2008 French guidelines on kindergarten programmes recommend teacher presence to monitor the order/direction of strokes produced and trace quality, which allows corrective feedback if necessary. In the literature, this recommendation refers to the beneficial role of training and $\mathrm{KR}$ in motor learning (Schmidt and Lee, 2005). As one-to-one instruction in a classroom is not possible, we asked the teachers to specify in which phase of the learning process, for cursive writing activities, they felt that teacher presence was necessary: the first choice was gesture discovery, the second institutionalization and for one third of them, training. If we consider, with the exception of the free exploration phase, that teacher presence is essential for each of the other phases, results show that teachers are physically unable to implement government recommendations. The skills assessment phase is rarely chosen, which is probably due to the difficulty of taking into account the dynamic of the written trace. Validation is probably carried out on the basis of the traces left by the child and not on the dynamic characteristics of production. These choices are probably specific to professional constraints (class size) but could also indicate a lack of training or access to the scientific knowledge justifying a decision based on the written process rather than the product. The majority of teachers do not consider their presence to be essential during the training phase as it is physically impossible to be next to each pupil when they are writing. Further interview-based studies would 
be necessary to ensure that these teaching practices are not intrinsic to the educational beliefs associated with the notion of training. From these findings, a digital tablet appears to be a useful learning tool for cursive handwriting that can be adapted to pupil needs. This is innovative for multiple reasons: it enables the classroom learning environment to be adapted to pupil needs as teachers can stay with some pupils discovering the writing gesture, while others can practise independently; it provides immediate feedback during the training phases (Van der Kleij et al., 2015); and for teachers, it can be used in assessments as written products can be replayed and dynamic characteristics of the product (localization of stops, stroke order and direction) accessed.

The third institutional recommendation analyzed in this study concerned teachers' ability to manage classroom diversity (MEN, 2013). First, teachers were asked if they managed diversity in the learning to write process, then to clarify how they managed the difficulties encountered by pupils in this learning process by specifying the help they usually proposed. Although over 85 per cent of respondents said they provided support for diverse learners, the approaches adopted were often unclear as 10 per cent of them did not volunteer this information and 28 per cent of them stated professional action without going into further detail. This finding leads us to think that managing the diversity of learning rhythms and pupil difficulties during the learningto-write process is complex and professionally difficult for French teachers, but it is not specific to the French school context (Graham et al., 2007; Labrecque et al., 2013). For the teachers who describe the activities for pupils with learning difficulties, 19 per cent mention fine or gross motor skill activities, but the perceptual component is mentioned only once. Most often, teachers help pupils by diversifying the media (sand, flour, semolina and erasable writing pad) used to train gesture. Most solutions involve reducing the degree of friction between the tool and the graphic surface or producing traces directly with the finger to temporarily eliminate penhold. Recently, Patchan and Puranik (2016) showed the benefit of finger-based rather than stylus-based tablet training, which reinforces the idea that decreasing the degree of friction or removing the pen is beneficial to learning. Diversification of media was also observed in the same way by Baraud et al. (2018). Variability in motor learning has been interpreted as a positive and necessary element in motor learning (Bernstein, 1996; Schmidt and Lee, 2005). Change to media and tools (sand, flour, semolina, erasable writing pad, fingers, pencils, etc.) during the learning process offers children a field of promoted actions in which the exploration of the sensory, perceptual, tonic 
and postural components linked to handwriting skills is nurtured (Bara et al., 2011 ; Bara and Bonneton-Botté, 2017). From this point of view, writing on a digital tablet should be considered and presented to French teachers as a medium that can enrich, not replace, what already exists. The anecdotal use of digital tools among French kindergarten teachers to teach cursive writing shows that there is still a lot of work that needs to be done to explore, demonstrate and publicize the relevance of such devices. For example, it seems that they could be used for the perceptual component of writing motor skills - rarely addressed by respondents - because they offer learners the possibility to replay their model with a dynamic visual model (BonnetonBotté et al., 2018; Jolly et al., 2013; Vinter and Chartrel, 2010).

Finally, an interesting result obtained in this research concerns teachers' perception of the written trace left on a digital tablet. Most of them intuitively establish a difference, from the point of view of the child, between the trace left on paper and the trace left on a screen, and only 12 per cent of them mention the impermanence of the digital trace. How can a child, whose semiotic function is under construction, engage in a writing activity if their production is not intended to be read and if the surface on which they have left traces becomes a blank screen at the end of the activity? If the amount of exposure to print and to print-related activities is decisive for reading skills, as stated by Puranik and Lonigan (2009), the emergence of new media for handwriting poses new challenges to developmental psychology, which will have to interweave the advent of digital writing with the development of semiotic function.

\section{Limitations}

As with all surveys, a key limitation in this study is the reliance on selfreported data. If we assume that teachers' answers are reliable, we also know that some of their answers may seek to match social and institutional expectations, that is, social desirability. We assume that the teachers interpreted the items when they answered. This effect is systematic during survey research and requires that other complementary methodologies be developed such as classroom observations or interview.

\section{Conclusions}

French government recommendations and scientific knowledge on the acquisition of fluid and legible cursive writing lead us to consider the cognitive 
(symbolic, semiotic and semantic), perceptual and motor components during the learning process. Previous research has also emphasized the need for substantial training time for writing to become automated, varied teaching situations and immediate access to KR during the learning process. Our contribution has shown that it is not easy for teachers to integrate all these constraints. Beyond its motivational benefits, using a digital tablet as a classroom tool to acquire handwriting skills must be simultaneously acceptable and efficient irrespective of learner needs and characteristics. The results obtained contributed to the development of some recommendations during the 'Kaligo' application design process. In particular, we stress the need of for a guidebook for teachers to make explicit the specificities of this application. This guide explains how the exercises implemented in the application correspond to current institutional and scientific recommendations. The guide is also helpful to make clear the availability of different adaptive pedagogical scenarios designed to adjust exercises to each child's difficulties (i.e. a one-toone instruction) - an adaptation based on the automatic analysis of handwritten productions. As all children's productions are recorded, the guide mentions that a precise analysis of children's writing (i.e. order, direction and shape) is possible for teachers (in-class or after), which could help them to understand children's writing skills and difficulties (for example they can replay their writing). Finally, as the question of the status of the trace written on a tablet is important for teachers, we underline that the children's production can be easily printed and thus used by the teacher or taken home. Even if digital media can be useful and interesting for handwriting teaching, the guidebook reminds us that teachers have to keep in mind that the tablet is only one medium among others that can enrich the possibilities of exercising in different contexts.

\section{Funding}

The author(s) received no financial support for the research, authorship and/or publication of this article.

\section{Notes}

1. Translated from French.

2. Idem.

3. Idem.

\section{ORCID iD}

Nathalie Bonneton-Botte (D) http://orcid.org/0000-0003-0462-1691 


\section{References}

Accardo AP, Genna M and Borean M (2013) Development, maturation and learning influence on handwriting kinematics. Human Movement Science 32(1): $136-146$.

Alamargot D and Morin M-F (2015) Does handwriting on a tablet screen affect students' graphomotor execution? A comparison between grades two and nine. Human Movement Science 44: 32-41.

Amadieu F and Tricot A (2014) Apprendre avec le numérique: mythes et réalités [Learning with digital]. Parsi: Retz. DOI:10.14375/np.9782725633206.

Bara F and Bonneton-Botté N (2017) Learning letters with the whole body: Visuomotor versus visual teaching in kindergarten. Perceptual and Motor Skills 125(1): 190-207.

Bara F, Morin MF, Alamargot D, et al. (2016) Learning different allographs through handwriting: The impact on letter knowledge and reading acquisition. Learning and Individual Differences 45: 88-94.

Bara F, Morin M-F, Montésinos-Gelet I, et al. (2011) Conceptions et pratiques en graphomotricité chez des enseignants de primaire en France et au Québec [Conceptions and graphomotor practices among primary teachers in France and Quebec]. Revue Française de Pédagogie 176: 41-56.

Baraud, M., Bril, B., \& Acioly-Régnier, N. M. (2018). Pratiques enseignantes pour l'apprentissage de l'écriture en grande section de maternelle et au cours préparatoire en France. Education didactique, 12(2), 73-88.

Berninger VW, Nagy W, Tanimoto S, et al. (2015) Computer instruction in handwriting, spelling, and composing for students with specific learning disabilities in grades 4-9. Computers \& Education 81: 154-168.

Berninger VW, Vaughan K, Abbott RD, et al. (2002) Teaching spelling and composition alone and together: Implications for the simple view of writing. Journal of Educational Psychology 94(2): 291-304.

Bernstein NA (1996) Resources for ecological psychology. Dexterity and its development. In: ML Latash and MT Turvey (eds), Hillsdale: Lawrence Erlbaum Associates, Inc.

Boissiere J, Fau S and Pedro F (2013) Le numérique une chance pour l'école. Paris: Armand Colin.

Burnett C (2010) Technology and literacy in early childhood educational settings: A review of research. Journal of Early Childhood Literacy 10(3): 247-270.

Bonneton-Botté N, Beucher-Marsal C and Muller J (in press). Des pratiques innovantes aux pratiques traditionnelles d'enseignement de l'écriture cursive. Chapitre publié aux Presses Universitaires de Bordeaux.

Bonneton-Botté N, Bara F, Marec-Breton N, et al. (2018) Writers' and pre-writers' perception of the cursive handwriting movement. Reading and Writing 31(4): 927-943.

Bril B (2002) Apprentissage et contexte [Learning and context]. Intellectica 35(2): 251-268. 
Chickering AW and Ehrmann SC (1996) Implementing the seven principles: Technology as lever. AAHE Bulletin 49: 3-6.

Choi SY, Kang YS and Lee H (2008) The effects of socio-technical enablers on knowledge sharing: An exploratory examination. Journal of Information Science 34(5): $742-754$.

Danna J and Velay JL (2015) Basic and supplementary sensory feedback in handwriting. Frontiers in Psychology, Epub ahead of print 20 February 2015. DOI: 10.3389/ fpsyg.2015.00169.

Dillman D, Smyth J and Christian LM (2009) Internet, mail, and mixed-mode surveys: The tailored design model. 3rd ed. Hoboken: Wiley.

Dragemark Oscarson A (2009) Collaboration in understanding results - Self-assessment of EFL writing. Bern: Peter Lang D.

Ferrière S, Cottier P, Lacroix F, et al. (2012) Dissémination de tablettes tactiles en primaire et discours des enseignants: Entre rejet et adoption. Sciences et Technologies de l'Information et de la Communication pour l'Éducation et la Formation (20): 153-176.

Flewitt R, Messer D and Kucirkova N (2014) New directions for early literacy in a digital age: The iPad. Journal of Early Childhood Literacy 15(3): 289-310.

Goh CCM, Zhang LJ, Ng CH, et al. (2005) Knowledge, beliefs and syllabus implementation: A study of English language teachers in Singapore. Singapore: Graduate Programmes and Research Office, National Institute of Education, Nanyang Technological University.

Graham S, Harris KR, Mason L, et al. (2007) How do primary grade teachers teach handwriting? A national survey. Reading and Writing 21(1-2): 49-69.

Hoy MMP, Egan MY and Feder KP (2011) A systematic review of interventions to improve handwriting. Canadian Journal of Occupational Therapy 78(1): 13-25.

Jolly C, Palluel-Germain R and Gentaz E (2013) Evaluation of a tactile training for handwriting acquisition in French kindergarten children: A pilot study. Kindergartens: Teaching methods, Expectations and Current Challenges, 161-176.

Kluger AN and DeNisi A (1996) The effects of feedback interventions on performance: A historical review, a meta-analysis, and a preliminary feedback intervention theory. Psychological Bulletin 119(2): 254-284.

Labrecque A-M, Morin M-F and Montésinos-Gelet I (2013) Quelle place est accordée à la composante graphomotrice de l'écriture dans les classes au début du primaire? Enquête auprès d’enseignants québécois. Nouveaux C@hiers de La Recherche En Éducation 16(1): 104 .

Lankshear C and Knobel M (2003) New technologies in early childhood literacy research: A review of research. Journal of Early Childhood Literacy 3(1): 59-82.

Longcamp M, Boucard C, Gilhodes J-C, et al. (2008) Learning through hand- or typewriting influences visual recognition of new graphic shapes: Behavioral and functional imaging evidence. Journal of Cognitive Neuroscience 20(5): 802-815.

McCarthey, S. J. (2008). The impact of No Child Left Behind on teachers' writing instruction. Written Communication 25(4): 462-505. 
McKenna C (2012) There's an app for that: How two elementary classrooms used iPads to enhance student learning and achievement. Education 2(5): 136-142.

Medwell J and Wray D (2008) Handwriting-A forgotten language skill? Language and Education 22(1): 34-47.

Meulenbroek RGJ and van Galen GP (1988) The acquisition of skilled handwriting: Discontinuous trends in kinematic variables. Cognition and Action in Skilled Behaviour 55: 273-281.

Ministère de l'éducation nationale (2006) Documents d'accompagnement : Le langage au cœur des apprentissages [Accompanying documents: Language at the heart of learning]. Available at: http://eppee.ouvaton.org/spip.php?article66 (accessed 7 March 2019).

Ministère de l'éducation nationale (2008) Programme français d'enseignement de l'école maternelle [French kintergarten school syllabus]. Available at: http:// eppee.ouvaton.org/spip.php?article66 (accessed 7 March 2019).

Ministère de l'éducation nationale (2013) Référentiel de compétences des métiers de l'enseignement et de l'éducation [Competency framework for the teaching and education professions]. Available at: http://www.education.gouv.fr/cid 73215/le-referentiel-de-competences-des-enseignants-au-bo-du-25-juillet-2013. html (accessed 7 March 2019).

Ministère de l'éducation nationale (2015) Programme français d'enseignement de l'école maternelle [French kintergarten school syllabus]. Available at: http:// eppee.ouvaton.org/spip.php?article66 (accessed 7 March 2019).

Paoletti RF (1994) Les composantes motrices de l'écriture manuscrite : Enquête sur les pratiques pédagogiques en maternelle et en première année. Revue des Sciences de l’Éducation 20: 317-329.

Patchan MM and Puranik CS (2016) Using tablet computers to teach preschool children to write letters: Exploring the impact of extrinsic and intrinsic feedback. Computers \& Education 102: 128-137.

PBS Learning Media (2015) The future of digital learning. Available at: https://gpb. pbslearningmedia.org/resource/26524f73-498a-4607-ae61-66d6a8903e1f/thefuture-of-digital-learning (accessed 7 March 2019).

Porter RE, Fusarelli LD and Fusarelli BC (2014) Implementing the common core. Educational Policy 29(1): 111-139.

Puntambekar S and Hubscher R (2005) Tools for scaffolding students in a complex learning environment: What have we gained and what have we missed? Educational Psychologist 40(1): 1-12.

Puranik CS and Lonigan CJ (2009) From scribbles to scrabble: Preschool children's developing knowledge of written language. Reading and Writing 24(5): 567-589.

Puranik C, Lonigan CJ and Kim YS (2011) Contributions of emergent literacy skills to name writing, letter writing, and spelling in preschool children. Early Childhood Research Quarterly 26: 465-474. 
Puranik C, Petscher Y and Lonigan CJ (2014) Learning to write letters: Examination of student and letters factors. Journal of Experimental Child Psychology 128: 152-170.

Rogers LA and Graham S (2008) A meta-analysis of single subject design writing intervention research. Journal of Educational Psychology 100(4): 879-906.

Rosenblum S, Goldstand S and Parush S (2006) Relationships among biomechanical ergonomic factors, handwriting product quality, handwriting efficiency, and computerized handwriting process measures in children with and without handwriting difficulties. American Journal of Occupational Therapy 60(1): 28-39.

Salmoni AW, Schmidt RA and Walter CB (1984) Knowledge of results and motor learning: A review and critical reappraisal. Psychological Bulletin 95(3): 355-386. doi:10.1037/0033-2909.95.3.355.

Schmidt RA and Lee TD (2005) Motor control and learning. A behavioral emphasis. 5th ed. Champaign: Human Kinetics.

Schmitz C (2016) LimeSurvey (version 2.56.1) [Software]. Available at: https:// www.limesurvey.org/ (accessed 7 March 2019).

Schwellnus H, Cameron D and Carnahan H (2012) Which to choose: Manuscript or cursive handwriting? A review of the literature. Journal of Occupational Therapy, Schools, \& Early Intervention 5(3-4): 248-258.

Simonnet D, Anquetil E and Bouillon M (2017) Multi-criteria handwriting quality analysis with online fuzzy models. Pattern Recognition 69: 310-324.

Thibon LS, Gerber S and Kandel S (2018) The elaboration of motor programs for the automation of letter production. Acta Psychologica 182: 200-211.

Tricot A, Plégat-Soutjis F, Camps JF, et al. (2003, Avril) Utilité, utilisabilité, acceptabilité: Interpréter les relations entre trois dimensions de l'évaluation des EIAH. In: ATIEF/INRP (eds) Environnements Informatiques pour l'Apprentissage Humain 2003. Paris: ATIEF/INRP, pp. 391402.

Troia GA and Graham S (2016) Common core writing and language standards and aligned state assessments: A national survey of teacher beliefs and attitudes. Reading and Writing 29(9): 1719-1743.

Van der Kleij FM, Feskens RC and Eggen TJ (2015) Effects of feedback in a computerbased learning environment on students' learning outcomes: A meta-analysis. Review of Educational Research 85(4): 475-511.

Vinter A and Chartrel E (2010) Effects of different types of learning on handwriting movements in young children. Learning and Instruction 20(6): 476-486.

Warschauer M (2007) A teacher's place in the digital divide. Yearbook of the National Society for the Study of Education 106(2): 147-166. 